\title{
ENSINO TÉCNICO PÚBLICO: AS PERCEPÇÕES DOS PROVEDORES DO ENSINO E DOS ALUNOS INGRESSANTES
}

\author{
Cristiane Souza de Lacerda, Arilda Teixeira \\ Fucape Business School
}

DOI: $10.15628 /$ rbept.2019.7804

Artigo submetido em set/2018 e aceito em set/2019

\begin{abstract}
RESUMO
O objetivo deste artigo foi identificar o gap de conhecimento entre o que os alunos entrantes esperam da Instituição de Ensino (IE) e o que os provedores desses serviços consideram que os alunos esperam. Foi realizada uma pesquisa descritiva, quantitativa, com corte transversal. Os dados foram obtidos através da replicação do questionário utilizado por Margotto (2014) com alterações. O questionário foi aplicado em 1485 candidatos aos cursos, e em 386 servidores da instituição de ensino. A amostra foi não probabilística por conveniência. Os dados foram estimados através de estatística descritiva e regressões lineares múltiplas. Os resultados sugeriram que os inscritos no processo seletivo esperam muito mais do ensino do que os servidores consideram que eles esperem. Isso permite admitir que os servidores percebem apenas parte das expectativas do futuro aluno em relação ao curso e à IE; a necessidade de a IE ajustar sua gestão de maneira a ser capaz de atender às expectativas dos alunos e com isso estabelecer uma efetiva relação de atração e lealdade para com eles.
\end{abstract}

Palavras-Chave: Comportamento do Consumidor. Gap de conhecimento. Análise de Percepção. Instituições de ensino.

\section{PUBLIC TECHNOLOGICAL TEACHING: THE PERCEPTIONS FROM THE INSTITUTIONAL MEMBERS AND FROM THE FRESHMEN STUDENTS}

\begin{abstract}
The paper aims to identify the knowledge gap between the freshmen students expectations about the Teaching Institution (IE), as well as the Teaching Institution opinion about the students expectations on the Institution. It was a descriptive, quantitative, cross-sectional research. The data was obtained through the replication of the questionnaire used by Margotto (2014) with changes. That questionnaire was applied in 1485 freshmen students and in 386 servers of the Institution. The sample was non-probabilistic for convenience. The Data were estimated through descriptive statistics and multiple linear regressions. The results suggested that those freshmen students expect much more from the Teaching Institution than the servers expect them to expect. These results allows to admit that the servers perceive only part of the freshmen students expectations in relation to the Institution; and the need to the Institution management adjustment so as to be able to meet the expectations of students and thereby establish an effective relationship of attraction and loyalty to them.
\end{abstract}

Keywords: Consumer Behavior. Gap of Knowledge. Perception Analysis. Teching Institution. 


\section{INTRODUÇÃO}

Diante da instabilidade econômica, política e social, a mensuração da percepção de qualidade pelo cliente, bem como da tomada de decisões que gerem melhoria dos serviços sob a ótica desse mesmo cliente, mostra-se essencial para a competitividade das instituições (LIMA, 2015).

Para favorecer a avaliação da qualidade nos serviços, Parasuraman, Zeithaml e Berry (1985) propuseram o Modelo de Análise dos 5 Gaps da Qualidade (Modelo de Gaps), a partir de uma estrutura que compara expectativas e percepções de desempenho. Esse modelo aponta as discrepâncias entre as percepções de qualidade dos serviços prestados, pelo prestador e pelo cliente.

Dentre os Gaps do modelo, destaca-se o Gap 1, também chamado de Gap de percepção. Esse Gap aponta a qualidade de um serviço, pois evidencia o grau de discrepância entre a real expectativa do usuário e as percepções do prestador do serviço sobre essas expectativas (PARASURAMAN; ZEITHALML; BERRY, 1991). De acordo com os proponentes do modelo, ele se aplica a qualquer tipo de serviço, incluindo os serviços prestados por instituições de ensino (IE).

Cabe salientar que, para gerenciar os fatores que causam discrepância entre expectativas e desempenho de uma IE, faz-se necessário identificar as diferenças existentes entre as expectativas dos alunos e a percepção que os provedores do serviço têm acerca dessas expectativas. Davies (2002) afirmou que identificar o que os alunos esperam interfere na prestação de serviços, pois, assim, professores, gestores educacionais e técnicos administrativos gerenciam as expectativas dentro das limitações e possibilidades da instituição a fim de conquistar a satisfação dos alunos.

Conhecer e explorar o que os ingressantes esperam do curso e da instituição pode ajudar as IEs a identificarem as causas das taxas crescentes de evasão, bem como subsidiar a elaboração de programas e projetos institucionais de impacto educacional e social (MARINHO-ARAÚJO et al., 2015).

Mainardes (2010, p. 348) sugeriu uma investigação sobre o Gap entre as percepções de alunos e a dos gestores de instituições de ensino. Ele questionou se há diferença entre o que o um cliente em potencial espera e 0 que $o$ gestor acha que o cliente pensa. Tal sugestão motivou esta pesquisa, que teve por objetivo identificar o Gap de conhecimento entre o que os futuros alunos esperam da Instituição de Ensino (IE) e a percepção que os provedores desse serviço têm sobre o que os alunos esperam.

A linha de abordagem aqui adotada foi utilizada por Margotto (2014) para medir o Gap 1 entre alunos e professores. Ao final, ela sugeriu novas pesquisas sobre a percepção dos gestores e da equipe administrativa 
comparadas às expectativas dos alunos, o que indica, portanto, uma lacuna na literatura, que este estudo se propôs a cobrir.

É importante que os provedores do serviço estejam alinhados com as expectativas dos potenciais alunos devido ao problema recorrente de evasão de alunos que as IEs têm enfrentado. Atender às expectativas desses alunos aumenta a sua atratividade e constrói lealdade (MAINARDES; ALVES; RAPOSO, 2013). Assim, a relevância deste trabalho é que seus resultados poderão contribuir para: (i) identificar as percepções dos alunos que não estão sendo devidamente atendidas; (ii) direcionar melhor as decisões da IE voltadas para melhorar a qualidade; (iii) identificar focos de insatisfação que podem levar à evasão.

\section{REFERENCIAL TEÓRICO}

\subsection{MODELO PARA A QUALIDADE}

Para Miguel e Salomi (2004), a relevância alcançada pelo setor de serviços explica o papel dos instrumentos de mensuração da qualidade. Dentre os modelos estruturados para isso, cabe destacar o de Parasuraman, Zeithaml e Berry (1985), que apresentaram o Modelo dos 5 Gaps em que o Gap 1 corresponde à discrepância entre as expectativas do cliente e a percepção que a gerência tem sobre essas expectativas; o Gap 2, à diferença entre as percepções que a gerência tem das expectativas dos clientes e as especificações da qualidade do serviço; o Gap 3, à discrepância entre as especificações da qualidade e a prestação de um serviço; o Gap 4, à diferença entre o serviço prestado e a comunicação externa com os clientes; e o Gap 5, à diferença entre o que o cliente espera receber e a percepção que ele tem dos serviços ofertados. Como o Gap 1 se alinha ao objetivo deste trabalho, foi utilizado o Modelo de Qualidade dos 5 Gaps, e testado apenas o Gap 1.

Marimuthu e Ismail (2012) recomendaram o Modelo dos 5 Gap para pesquisas empíricas envolvendo IE. Para eles, este modelo permite identificar se as decisões que estão sendo tomadas estão alinhadas com as expectativas dos alunos. Xavier (2010) avaliou a qualidade dos serviços de uma instituição de ensino superior através do Modelo dos 5 Gaps.

Neste estudo, o Gap 1 compreende a diferença entre as expectativas dos candidatos a uma vaga no ensino técnico, e a percepção que os provedores do serviço têm acerca dessas expectativas. Saber se as decisões tomadas pela instituição estão coerentes com as expectativas dos alunos pode ser fundamental para a atratividade e lealdade dos futuros alunos (MAINARDES; ALVES; RAPOSO, 2013). Decisões erradas geram insatisfação do aluno. Por tais razões Mainardes (2010) destacou que as IE 
precisam entender os desejos e expectativas dos seus públicos de interesse para que os esforços adotados para melhorar a qualidade do serviço sejam adequados e os investimentos não sejam desperdiçados.

\subsection{QUALIDADE NAS INSTITUIÇÕES DE ENSINO}

A Lei de Diretrizes e Bases da Educação Nacional (LDB) (BRASIL, 1996), foi determinante para que as IE investissem em qualidade pois acirrou a competição entre elas devido ao aumento da oferta de escolas (MAINARDES; DOMINGOS, 2010).

Segundo Gronroons (1994), um meio de gerenciar a qualidade de um serviço prestado, é considerar a percepção que os clientes têm dele. Michael (1997), apontou que as IE devem adotar métodos de gestão capaz de implantar um sistema de qualidade total voltado para o aluno. Davies (2002) corrobora tal asserção ao afirmar que as organizações acadêmicas devem considerar os estudantes como legítimos clientes. Devem, portanto, identificar e administrar as expectativas dos alunos que estão entrando na instituição.

\subsection{EXPECTATIVAS DOS ALUNOS}

As IE podem agir de forma eficiente, dentro de suas limitações desde que conheçam as expectativas de seus alunos e o quanto essas expectativas influenciam suas satisfações (DAVIES, 2002). Para Marimuthu e Ismael (2012) deve-se levar em consideração que as expectativas dos alunos mudam e outras percepções vão sendo criadas. Assim há necessidade de se acompanhar initerruptamente suas opiniões para que essa compreensão seja atual e voltada ao futuro. Margotto (2014) afirma que a relação entre a instituição e o estudante, antes e durante a prestação do serviço, é influenciada pelas expectativas do aluno.

Em geral, expectativas atendidas geram satisfação para o aluno, podendo diminuir a evasão e gerar resultados positivos para as IE. Para Appleton-Knapp e Krentler (2006), os alunos que tiveram suas expectativas atendidas e, em alguns casos, superadas, estavam mais satisfeitos do que aqueles alunos para quem a experiência ficou abaixo das expectativas.

Teeroovengadum et al. (2016), apontaram como fatores determinantes da satisfação dos alunos o serviço administrativo, a infraestrutura e a qualidade no ensino. E, assim como Marinho-Araújo et al. (2015), apontaram que expectativa atendida é sinônimo de qualidade para uma IE. Tais apontamentos denotam quão relevante são essas variáveis, e a necessidade de a IE estar alinhada a eles para evitar a evasão (DAVIES, 2002; CASTRO et al., 2007; MARIMUTHU; ISMAEL, 2012; APPLETON- 
KNAPP; KRENTLER, 2006; MAINARDES, 2010; MARGOTTO, 2014; MARINHO-ARAÚJO et al., 2015; TEEROOVENGADUM et al., 2016).

\section{METODOLOGIA}

Foi realizada uma pesquisa quantitativa, descritiva, com dados primários e corte transversal, obtidos através da aplicação de questionários estruturados com opções de resposta em escala likert de um a cinco (um, "discordo totalmente"; cinco, "concordo totalmente"). Foram aplicados dois tipos de questionários: um para os inscritos no processo seletivo da Instituição de ensino e outro para os servidores. Também foi realizado teste $t$ de comparação de médias e regressões lineares múltiplas.

A Instituição estudada foi o Instituto Federal de Educação Ciência e Tecnologia do Maranhão (IFMA), que oferece cursos técnicos e superiores em diversas áreas. A escolha dessa instituição deveu-se ao fato de ser importante para todas as IEs, identificar os atributos que geram a satisfação do estudante para o combater à evasão e a atrair novos alunos.

Por se tratar de um estudo comparativo, foram selecionadas duas populações: os inscritos no processo seletivo de 2016 do IFMA; e os servidores do instituto, que incluiu gestores, professores e a equipe técnica administrativa. A escolha da primeira justifica-se em razão de a relação entre a IE e os discentes envolver as expectativas dos estudantes antes mesmo da prestação de serviços (MARGOTTO, 2014); a da segunda, pelo fato de os serviços de todos os servidores -acadêmicos ou não - interferirem direta ou indiretamente na formação de expectativas dos alunos. Além disso, Margoto (2014) sugeriu que o pessoal não acadêmico fosse investigado.

Foi escolhido o Gap 1 do Modelo dos 5 Gaps de Parasuraman, Zeithalm e Berry (1985) porque este trabalho é um estudo comparativo de percepções; e, segundo os autores, através do Gap 1 é possível comparar as diferenças entre o que os provedores de um serviço acreditam que os clientes esperam, e as reais expectativas desses clientes. Ou seja, os resultados apontarão a direção das decisões para atender as expectativas dos alunos. As expectativas utilizadas no questionário são as que foram sugeridas por Margotto (2014) - relativas a aspectos acadêmicos e não acadêmicos relacionados ao curso e à instituição de ensino. Cada expectativa foi transformada em uma frase afirmativa e acompanhada por uma escala de concordância com a respectiva afirmativa.

Tratando-se de uma replicação do estudo feito por Margotto (2014), foram inseridas, duas variáveis: uma que trata do grau de expectativa geral em relação ao curso e em relação à instituição estudada (se é muito baixa, baixa, média, alta e muito alta); a outra contendo os dados sociodemográficos dos inscritos no processo seletivo de 2016. 
A escala de mensuração utilizada foi a de Margotto (2014) que foi replicada neste estudo. A aplicação dos questionários aos inscritos ocorreu no ato da inscrição para o processo seletivo de 2016, que aconteceu entre os meses de setembro e outubro de 2015. Ao término da inscrição online, o candidato era convidado a participar, voluntariamente, clicando no link da pesquisa. Foram respondidos 1.485 questionários de uma população de 29.392 inscritos. Como se trata de um estudo comparativo, o instrumento de coleta de dados aplicado aos servidores foi uma adaptação das trinta afirmações coletadas dos futuros alunos, para que o servidor indicasse seu grau de concordância quanto ao que ele achava que o futuro aluno esperava.

Para o questionário dos servidores, foi inserida uma pergunta de controle, para identificar se o respondente era servidor do IFMA. Também foram acrescentadas perguntas para o perfil sociodemográfico; se o servidor participa de algum órgão colegiado; e se o trabalho dele é de atendimento direto ao aluno. O questionário foi enviado por e-mail de todos os 2.784 servidores. Foram respondidos 386.

\section{ANÁLISE DE DADOS}

\subsection{CARACTERIZAÇÃO DA AMOSTRA}

Conforme Tabela 1 - amostra dos inscritos - a distribuição entre os gêneros está dividida meio-a-meio; e a faixa etária predominante é a de entre 12 e 17 anos (65,9\%). A maioria absoluta não trabalha (82,5\%), mas $78,9 \%$ pretende trabalhar na área em que está fazendo o curso. Mais de $50 \%$ escolheu a modalidade de curso Integrado ao Ensino Médio.

TABELA 1 - CARACTERIZAÇÃO DA AMOSTRA DOS INSCRITOS NO PROCESSO SELETIVO

\begin{tabular}{l|l|c|c}
\hline \multicolumn{2}{c|}{ Características } & Frequência & $\%$ \\
\hline \multirow{2}{*}{ Gênero } & Feminino & 698 & $47 \%$ \\
& Masculino & 787 & $53 \%$ \\
\hline \multirow{4}{*}{ Faixa etária } & 12 e 17 anos & 979 & $65,90 \%$ \\
\cline { 2 - 4 } & 18 e 24 anos & 332 & $22,40 \%$ \\
\cline { 2 - 4 } & 25 e 30 anos & 95 & $6,40 \%$ \\
\cline { 2 - 4 } & 31 e 52 anos & 79 & 5,3 \\
\hline \multirow{2}{*}{ Trabalha? } & SIM & 260 & 17,5 \\
\cline { 2 - 4 } & NÂO & 1225 & 82,5 \\
\hline \multirow{2}{*}{$\begin{array}{l}\text { Já trabalha ou pretende trabalhar na do curso que você escolheu } \\
\text { área }\end{array}$} & SIM & 1172 & 78,9 \\
\cline { 2 - 4 } & NÃO & 313 & 21,1 \\
\hline
\end{tabular}




\begin{tabular}{l|l|c|c} 
& $\begin{array}{l}\text { Concomitante ao Ensino } \\
\text { Médio }\end{array}$ & 168 & 11,3 \\
\cline { 2 - 4 } Modalidade do Curso escolhido & $\begin{array}{l}\text { Integrado ao Ensino } \\
\text { Médio }\end{array}$ & 783 & 52,7 \\
\hline & $\begin{array}{l}\text { Subsequente ao Ensino } \\
\text { Médio }\end{array}$ & 534 & 36 \\
\hline
\end{tabular}

Fonte: Dados da Pesquisa. Elaborado pelas autoras

Pelos dados da Tabela 2 - amostra dos servidores - a distribuição entre os gêneros também é equilibrada, $46,9 \%$ feminino e $53.1 \%$ masculino. Mais de $50 \%$ dos respondentes é servidor Técnico Administrativo; 93,3\% não participa de órgão superior e $63 \%$ atua no atendimento direto ao aluno.

TABELA 2 - CARACTERIZAÇÃO DA AMOSTRA DOS SERVIDORES

\begin{tabular}{l|l|c|c}
\hline \multicolumn{2}{c|}{ Características } & Frequência & $\%$ \\
\hline \multirow{2}{*}{ Gênero } & Feminino & 181 & 46,9 \\
\cline { 2 - 4 } & Masculino & 205 & 53,1 \\
\hline \multirow{2}{*}{ Cargo } & TAE* & 221 & 57,3 \\
\cline { 2 - 4 } & Professor & 165 & 42,7 \\
\hline \multirow{2}{*}{ Participa de órgão superior? } & SIM & 26 & 6,7 \\
\cline { 2 - 4 } & NÂO & 360 & 93,3 \\
\hline \multirow{2}{*}{ Trabalha no atendimento direto ao aluno } & SIM & 243 & 63 \\
\cline { 2 - 4 } & NÂO & 143 & $37,00 \%$ \\
\hline
\end{tabular}

Fonte: Dados da Pesquisa. Elaborado pelas autoras

$\left.{ }^{*}\right)$ TAE-Técnico Administrativo em Educação

\subsection{ESTATÍSTICA DESCRITIVA DOS INSCRITOS NO PROCESSO SELETIVO}

Os resultados da Tabela 3 apresentaram médias acima de quatro para todas as variáveis. Ou seja, houve, pelo menos, tendência a concordância dos inscritos com relação aos atributos apontados pelo Gap 1. Isso sugere que os inscritos tinham grandes expectativas quanto ao curso, dentre elas inclusive a de que viveriam uma nova experiência de vida ao ingressarem. Os interessados em ingressar no curso técnico concordaram que esperam mais do que uma formação profissional. Esperam também desenvolvimento humano e profissional. E essa opinião parece predominar entre eles dado os valores dos desvios-padrão. Resultados análogos foram encontrados por Appleton-knapp e Krentler (2006), Mainardes (2010), Margotto (2014), Marinho-Araujo et al. (2015) e Teeroovengadum et al. (2016).

As médias obtidas indicam que as expectativas dos inscritos são altas em relação aos atributos de qualidade apresentados. Em contrapartida, implicam na necessidade da IE de oferecer um serviço de qualidade para que não perca alunos. 
TABELA 3 - ESTATÍSTICA DESCRITIVA DA PERCEPÇÃO DOS INSCRITOS NO PROCESSO SELETIVO

\begin{tabular}{|c|c|c|c|}
\hline \multicolumn{2}{|r|}{ Variável } & \multirow{2}{*}{\begin{tabular}{c|} 
Média \\
4,3
\end{tabular}} & \multirow{2}{*}{$\begin{array}{l}\text { Desvio } \\
\text { Padrão } \\
0,898\end{array}$} \\
\hline $\mathrm{P} 1$ & O curso possuirá um alto grau de exigência & & \\
\hline P2 & Eu espero conseguir um bom emprego após o curso & 4,8 & 0,595 \\
\hline P3 & Eu espero fazer novos amigos e ter vida estudantil animada & 4,4 & 0,845 \\
\hline P4 & $\begin{array}{l}\text { Eu vou cursar disciplinas atualizadas, interessantes e ligadas à } \\
\text { realidade social e profissional }\end{array}$ & 4,7 & 0,62 \\
\hline P5 & $\begin{array}{l}\text { Eu espero apoio financeiro do Instituto por meio de programas de } \\
\text { bolsas e financiamentos }\end{array}$ & 4,3 & 1,012 \\
\hline P6 & Eu espero ter novas experiências pessoais e educacionais & 4,9 & 0,427 \\
\hline E7 & Eu espero encontrar boa estrutura física no Instituto & 4,8 & 0,571 \\
\hline P8 & $\begin{array}{l}\text { Eu espero encontrar serviços adequados às necessidades dos } \\
\text { alunos (bibliotecas, serviços acadêmicos, laboratórios, praça de } \\
\text { alimentação, entre outros) }\end{array}$ & 4,9 & 0,452 \\
\hline P9 & $\begin{array}{l}\text { Eu espero conseguir crescimento e desenvolvimento pessoal e } \\
\text { profissional com este curso }\end{array}$ & 4,9 & 0,376 \\
\hline P10 & $\begin{array}{l}\text { Eu espero encontrar Professores com vontade de ajudar, ouvir, } \\
\text { responder a perguntas e estarem disponíveis para os alunos }\end{array}$ & 4,9 & 0,459 \\
\hline $\mathrm{P} 11$ & Eu espero participar de investigações científicas & 4,6 & 0,716 \\
\hline P12 & $\begin{array}{l}\text { Eu espero ter acesso a todas às informações acadêmicas e não } \\
\text { acadêmicas do curso através de ferramentas online }\end{array}$ & 4,8 & 0,522 \\
\hline $\mathrm{P} 13$ & Eu espero ter acesso a tecnologias de última geração & 4,8 & 0,562 \\
\hline P14 & $\begin{array}{l}\text { Eu espero que o Instituto tenha fortes ligações com o mercado de } \\
\text { trabalho }\end{array}$ & 4,6 & 0,709 \\
\hline $\mathrm{P} 15$ & Eu espero ter liberdade de pensamento e expressão & 4,6 & 0,702 \\
\hline P16 & $\begin{array}{l}\text { Eu espero que haja partilha de conhecimento entre professores e } \\
\text { colegas }\end{array}$ & 4,8 & 0,53 \\
\hline P17 & $\begin{array}{l}\text { Eu espero realizar trabalhos voluntários em causas sociais da } \\
\text { localidade onde o Instituto está inserido }\end{array}$ & 4,7 & 0,555 \\
\hline P18 & $\begin{array}{l}\text { Eu espero, após a conclusão do curso, obter rápida estabilidade } \\
\text { financeira }\end{array}$ & 4,8 & 0,469 \\
\hline P19 & $\begin{array}{l}\text { Eu espero ampliar minhas capacidades pessoais com os novos } \\
\text { conhecimentos adquiridos }\end{array}$ & 4,5 & 0,775 \\
\hline P20 & $\begin{array}{l}\text { Eu espero encontrar no Instituto um ambiente agradável e propício } \\
\text { ao aprendizado }\end{array}$ & 4,5 & 0,823 \\
\hline P21 & $\begin{array}{l}\text { Eu pretendo, após a conclusão do curso Técnico, continuar meus } \\
\text { estudos por meio de uma graduação no Instituto }\end{array}$ & 4,9 & 0,391 \\
\hline P22 & $\begin{array}{l}\text { Eu acho que o professor utilizará todos os recursos disponíveis } \\
\text { para o planejamento do curso e execução das aulas }\end{array}$ & 4,9 & 0,416 \\
\hline P23 & $\begin{array}{l}\text { Eu espero que haja negociação dos métodos de ensino, } \\
\text { aprendizagem e avaliação entre alunos e professores }\end{array}$ & 4,7 & 0,59 \\
\hline P24 & $\begin{array}{l}\text { Eu espero encontrar uma comunicação precisa sobre os cursos, } \\
\text { procedimentos de avaliação e processo de reclamações }\end{array}$ & 4,4 & 0,891 \\
\hline P25 & $\begin{array}{l}\text { Eu espero que os Cursos tenham mais aulas práticas do que } \\
\text { teóricas }\end{array}$ & 4,6 & 0,676 \\
\hline P26 & $\begin{array}{l}\text { Eu espero encontrar honestidade na comunicação do Instituto para } \\
\text { responder às demandas dos alunos com respeito e autenticidade }\end{array}$ & 4,6 & 0,685 \\
\hline P27 & $\begin{array}{l}\text { Eu espero que os processos burocráticos do Instituto sejam bem } \\
\text { claros e definidos }\end{array}$ & 4,7 & 0,621 \\
\hline P28 & Eu espero que o Instituto promova eventos relacionados ao curso & 4,4 & 0,794 \\
\hline $\begin{array}{l}\text { Curs } \\
0\end{array}$ & Mir & 4,4 & 5 \\
\hline $\mathrm{IE}$ & Minha expectativa geral com relação ao Instituto é & 4,4 & 0,736 \\
\hline
\end{tabular}

Fonte: Dados da Pesquisa. Elaborado pelas autoras 


\subsection{ESTATÍSTICA DESCRITIVA DA AMOSTRA DOS SERVIDORES}

Os resultados da Tabela 4 sugerem que também houve predomínio de concordâncias entre os servidores quanto às expectativas dos alunos; o que demonstra que suas percepções quanto à qualidade do curso estão alinhadas com as dos alunos. Esse alinhamento ocorreu inclusive quanto ao grau de dispersão entre as opiniões, devido aos desvios-padrão abaixo da unidade. As exceções foram os atributos "participar de investigações científicas" (P11); "Ampliar minhas capacidades pessoais com os novos conhecimentos adquiridos" (P19); e "Encontrar no Instituto um ambiente agradável e propício ao aprendizado" (P20); nos quais as respostas dos alunos indicam a concordância e a dos servidores apenas que tendem a concordar. É possível interpretar essa diferença admitindo que os servidores subestimam o interesse do aluno por conhecimento - pesquisa, novos conhecimentos, aprendizado.

\section{TABELA 4 - ESTATÍSTICA DESCRITIVA DOS SERVIDORES}

\begin{tabular}{l|l|c|c}
\hline \multicolumn{1}{c|}{ Variável } & Média & $\begin{array}{c}\text { Desvio } \\
\text { Padrão }\end{array}$ \\
\hline E1 & O curso possuirá um alto grau de exigência & 4,2124 & 0,93778 \\
\hline E2 & Conseguir um bom emprego após o curso & 4,3212 & 0,94823 \\
\hline E3 & Fazer novos amigos e ter vida estudantil animada & 4,3446 & 0,83925 \\
\hline E4 & $\begin{array}{l}\text { Cursar disciplinas atualizadas, interessantes e ligadas à } \\
\text { realidade social e profissional }\end{array}$ & 4,5466 & 0,71652 \\
\hline E5 & $\begin{array}{l}\text { Apoio financeiro do Instituto por meio de programas de bolsas e } \\
\text { financiamentos }\end{array}$ & 4,0881 & 1,0654 \\
\hline E6 & Ter novas experiências pessoais e educacionais & 4,5337 & 0,69891 \\
\hline E7 & Encontrar boa estrutura física no Instituto & 4,8109 & 0,47041 \\
\hline E8 & $\begin{array}{l}\text { Encontrar serviços adequados às necessidades dos alunos } \\
\text { (bibliotecas, serviços acadêmicos, laboratórios, praça de }\end{array}$ & 4,7979 & 0,50514 \\
\hline E9 & $\begin{array}{l}\text { Conseguir crescimento e desenvolvimento pessoal e profissional } \\
\text { com esse curso }\end{array}$ & 4,6347 & 0,65563 \\
\hline E10 & $\begin{array}{l}\text { Encontrar professores com vontade de ajudar, ouvir, responder a } \\
\text { perguntas e estarem disponíveis para os alunos }\end{array}$ & 4,6762 & 0,63352 \\
\hline E11 & Participar de investigações científicas & 3,7953 & 1,04052 \\
\hline E12 & $\begin{array}{l}\text { Ter acesso a todas às informações acadêmicas e não } \\
\text { acadêmicas do curso através de ferramentas online }\end{array}$ & 4,5259 & 0,76996 \\
\hline E13 & Ter acesso a tecnologias de última geração & 4,2176 & 1,03913 \\
\hline E14 & Que o Instituto tenha fortes ligações com o mercado de trabalho & 4,0959 & 0,9796 \\
\hline E15 & Ter liberdade de pensamento e expressão & 4,3109 & 0,89543 \\
\hline E16 & Que haja partilha de conhecimento entre professores e colegas & 4,5389 & 0,7206 \\
\hline E17 & $\begin{array}{l}\text { Realizar trabalhos voluntários em causas sociais da localidade } \\
\text { onde o Instituto está inserido }\end{array}$ & 4,5751 & 0,69192 \\
\hline E18 & Após a conclusão do curso, obter rápida estabilidade financeira & 4,5363 & 0,70984 \\
\hline E19 & $\begin{array}{l}\text { Ampliar minhas capacidades pessoais com os novos } \\
\text { conhecimentos adquiridos }\end{array}$ & 3,4145 & 1,10216 \\
\hline E20 & $\begin{array}{l}\text { Encontrar no Instituto um ambiente agradável e propício ao } \\
\text { aprendizado }\end{array}$ & 3,8005 & 1,05884 \\
\hline
\end{tabular}




\begin{tabular}{l|l|c|c} 
E21 & $\begin{array}{l}\text { Após a conclusão do curso Técnico, continuar meus estudos por } \\
\text { meio de uma graduação no Instituto }\end{array}$ & 4,4819 & 0,75313 \\
\hline E22 & $\begin{array}{l}\text { Que o professor utilizará todos os recursos disponíveis para o } \\
\text { planejamento do curso e execução das aulas }\end{array}$ & 4,7694 & 0,49538 \\
\hline E23 & $\begin{array}{l}\text { Que haja negociação dos métodos de ensino, aprendizagem e } \\
\text { avaliação entre alunos e professores }\end{array}$ & 4,6036 & 0,64537 \\
\hline E24 & $\begin{array}{l}\text { Encontrar uma comunicação precisa sobre os cursos, } \\
\text { procedimentos de avaliação e processo de reclamações }\end{array}$ & 3,6891 & 1,02272 \\
\hline E25 & Que os Cursos tenham mais aulas práticas do que teóricas & 4,4948 & 0,73589 \\
\hline E26 & $\begin{array}{l}\text { Encontrar honestidade na comunicação do Instituto para } \\
\text { responder às demandas dos alunos com respeito e } \\
\text { autenticidade }\end{array}$ & 4,1062 & 0,93787 \\
\hline E27 & $\begin{array}{l}\text { Que os processos burocráticos do Instituto sejam bem claros e } \\
\text { definidos }\end{array}$ & 4,4326 & 0,8038 \\
\hline E28 & Que o Instituto promova eventos relacionados ao curso & 3,9067 & 1,07225 \\
\hline Curso & A expectativa geral do inscrito em relação ao CURSO é: & 4,0596 & 0,76214 \\
\hline IE & A expectativa geral do inscrito em relação ao Instituto é & 4,215 & 0,73353 \\
\hline F0: & Dasp da Pesqusa Ea &
\end{tabular}

Fonte: Dados da Pesquisa. Elaborado pelas autoras

A literatura mostra que as IEs decidem sobre investimentos e estratégias de desenvolvimento julgando saber o que os futuros alunos esperam. As estatísticas descritivas mencionadas neste trabalho apontaram que há possibilidade de 0 que a $\mathrm{IE}$ considera que $\mathrm{o}$ aluno espera não correspondem à expectativa do aluno. Isso significa a possibilidade de ela não atender àquelas expectativas. (MAINARDES, 2010; TEEROOVENGADUM et al., 2016).

\subsection{COMPARAÇÃO DAS MÉDIAS DE CADA VARIÁVEL DAS AMOSTRAS DOS INSCRITOS NO PROCESSO SELETIVO E DA AMOSTRA DOS SERVIDORES}

As médias das percepções quanto aos atributos foram iguais ou maiores que quatro nas duas amostras, sugerindo que os atributos foram considerados importantes tanto para os inscritos no processo seletivo quanto para os servidores. Contudo, as diferenças de médias nos atributos P11, P19, P20, P24, P28, apontam o Gap entre as percepções dos alunos e dos servidores

$O$ teste $t$ revelou que dois atributos não se demonstraram significativos quando comparados às amostras: P7 (Encontrar uma boa estrutura física no Instituto), e P3 (Fazer novos amigos e ter vida estudantil animada). Com relação a estas duas variáveis, não é possível afirmar que as percepções sejam diferentes.

Tomando esses resultados como base, é possível inferir que a IE necessita refletir sobre a forma que ela tem conduzido a formação dos futuros profissionais. Tais resultados apontaram que a expectativa do aluno transcende a uma formação tecnicista. Almejam também serem seres 
humanos mais evoluídos do que eram quando entraram na IE. Este resultado reafirma os achados por Margotto (2014) e Marinho-Araújo et al. (2015).

Concomitantemente, seus servidores atribuem menos importância ao diálogo, à qualidade da informação passada para o aluno, ao peso que a burocracia administrativa significa para ele, e a transparências de suas diretrizes, do que os alunos atribuem. Sugerem, então, a existência do Gap 1 de percepção (PARASURAMAN; ZEITHALML; BERRY, 1991), evidenciado através das diferenças de percepções entre inscritos no processo seletivo e os servidores, que por sua vez pode gerar insatisfação dos futuros alunos e a subsequente evasão (MARGOTTO, 2014).

\subsection{REGRESSÕES PARA VARIÁVEL DEPENDENTE "EXPECTATIVAS QUANTO AO CURSO" (CANDIDATOS INSCRITOS NO PROCESSO SELETIVO)}

Foram rodadas duas regressões para estimar os atributos que explicavam a expectativa dos alunos quanto ao curso. A primeira - Tabela 5 para identificar o percentual de explicação do modelo. Ela apontou que as variáveis explicativas explicavam $14,7 \%$ da variável dependente "expectativas dos alunos quanto ao curso".

TABELA 5 - PERCENTUAL DE EXPLICAÇÃO DO MODELO PELAS VARIÁVEIS EXPLICATIVAS

\begin{tabular}{|c|c|c|c|c|c|c|c|c|c|c|}
\hline \multirow[t]{2}{*}{ Modelo } & \multirow[t]{2}{*}{$\mathrm{R}$} & \multirow{2}{*}{$\begin{array}{c}\mathrm{R} \\
\text { quadrado }\end{array}$} & \multirow{2}{*}{$\begin{array}{c}\mathrm{R} \\
\text { quadrado } \\
\text { ajustado }\end{array}$} & \multirow{2}{*}{$\begin{array}{c}\text { Erro } \\
\text { padrão da } \\
\text { estimativa }\end{array}$} & \multicolumn{6}{|c|}{ Estatísticas de mudança } \\
\hline & & & & & $\begin{array}{c}\text { Alteração } \\
\text { de R } \\
\text { quadrado }\end{array}$ & $\begin{array}{c}\text { Alteração } \\
\text { F }\end{array}$ & df1 & df2 & $\begin{array}{c}\text { Sig. } \\
\text { Alteração } \\
\text { F }\end{array}$ & $\begin{array}{l}\text { Durbin- } \\
\text { Watson }\end{array}$ \\
\hline 8 & ,389h & 152, & 147, & 67916, & ,002 & 4,055 & 1 & 1476 & ,044 & 2,017 \\
\hline
\end{tabular}

. a. Preditores: (Constante), P1- o curso possuirá um alto grau de exigência; P25 - que os Cursos tenham mais aulas práticas do que teóricas; P2- conseguir um bom emprego após o curso; P23 - que haja negociação dos métodos de ensino, aprendizagem e avaliação entre alunos e professores; P24 encontrar uma comunicação precisa sobre os cursos, procedimentos de avaliação e processo de reclamações; P9 - conseguir crescimento e desenvolvimento pessoal e profissional com esse curso; P11- participar de investigações científicas; P4 - cursar disciplinas atualizadas, interessantes e ligadas à realidade social e profissional.

· b. Variável Dependente: Expectativa geral em relação ao CURSO

Método de estimação: Stepwise

Testes de validez:

-ANOVA: significativo

-Teste de Aleatoriedade: Aceita a hipótese de aleatoriedade

-Teste de Aderência Kolmogorov-Smirnov: Aceita hipótese de aderência à distribuição normal

-Teste de Homocedasticidade: Aceita a hipótese de homocedasticidade

Fonte: Dados da pesquisa. Elaborado pelo autor

A segunda regressão - Tabela 6 - foi rodada para identificar quais variáveis seriam estatisticamente relevantes para explicar a expectativa dos alunos em relação ao curso. Os resultados apontaram que, dentre as vinte e 
oito variáveis (atributos do Gap 1), as significantes foram: P1, P25, P2, P23, P24, P9, P11 e P4.

TABELA 6 - EXPECTATIVAS DOS ALUNOS: variáveis explicativas estatisticamente significantes

\begin{tabular}{|c|c|c|c|c|c|c|c|c|c|c|c|c|}
\hline$\frac{3}{\frac{3}{0}}$ & $\begin{array}{r}\text { Coe } \\
\text { tes } \\
\text { padr } \\
\text { d }\end{array}$ & $\begin{array}{l}\text { ien } \\
\text { ào } \\
\text { iza }\end{array}$ & $\begin{array}{c}\text { Coeficien } \\
\text { tes } \\
\text { padronizados }\end{array}$ & $\rightarrow$ & $\frac{\omega}{Q}$ & $\begin{array}{r}95 \\
\text { Inter } \\
\text { Cor } \\
\text { pe }\end{array}$ & $\begin{array}{l}0 \% \\
\text { alo de } \\
\text { ança } \\
\text { a B }\end{array}$ & \multicolumn{3}{|c|}{ Correlações } & \multicolumn{2}{|c|}{$\begin{array}{l}\text { Estatísticas de } \\
\text { colinearidade }\end{array}$} \\
\hline (Constante) & 816 & ,262 & & 3,112 & ,002 & ,302 & 1,331 & & & & & \\
\hline $\mathrm{P} 1$ &, 138 &, 020 & , 169 & 6,831 &, 000 & ,099 & 178 & ,242 & 175 & ,164 & ,939 & 1,065 \\
\hline P25 & , 103 & ,030 & ,095 & 3,446 & ,001 & ,045 & ,162 & ,237 & ,089 & ,083 & ,756 & 1,323 \\
\hline P2 & , 110 & ,032 & ,089 & 3,451 & ,001 & ,047 & ,172 & 200 & ,089 & ,083 & ,868 & 1,152 \\
\hline P23 & ,098 & ,033 & ,079 & 2,959 & ,003 & ,033 &, 163 & ,210 & ,077 & ,071 & ,810 & 1,235 \\
\hline P24 & ,067 & ,022 & ,081 & 3,073 & ,002 & ,024 & ,109 & 214 & ,080 & ,074 & ,831 & 1,204 \\
\hline P9 & ,128 & ,053 & ,065 & 2,393 & ,017 & ,023 & ,232 & ,224 & ,062 & ,057 & ,770 & 1,298 \\
\hline P11 & ,060 & ,027 & ,058 & 2,234 & ,026 & ,007 & ,112 & 184 & ,058 & ,054 & ,851 & 1,174 \\
\hline P4 &, 065 &, 032 & ,055 & 2,014 &, 044 & ,002 & ,128 & 208, & ,052 & ,048 & ,782 & 1,279 \\
\hline
\end{tabular}

Variável Dependente: Expectativa geral em relação ao CURSO

Fonte: Dados da pesquisa. Elaborado pelo autor.

Legenda:

P1 - o curso possuirá um alto grau de exigência;

P25 - que os Cursos tenham mais aulas práticas do que teóricas;

P2 - conseguir um bom emprego após o curso;

P23 - que haja negociação dos métodos de ensino, aprendizagem e avaliação entre alunos e professores;

P24 - encontrar uma comunicação precisa sobre os cursos, procedimentos de avaliação e processo de reclamações;

P9 - conseguir crescimento e desenvolvimento pessoal e profissional com esse curso;

P11- participar de investigações científicas;

P4 - cursar disciplinas atualizadas, interessantes e ligadas à realidade social e profissional.

\subsection{REGRESSÕES PARA ANÁLISE DA VARIÁVEL DEPENDENTE "EXPECTATIVAS DOS SERVIDORES SOBRE AS EXPECTATIVAS DOS ALUNOS"}

As regressões apontaram que as variáveis explicativas explicaram $14,4 \%$ das "expectativas dos servidores" - Tabela 7 -; e que as variáveis estatisticamente relevantes para explicar essas expectativas foram: $\mathrm{P} 9$ (conseguir crescimento e desenvolvimento pessoal e profissional com esse curso), P1(curso possuirá um alto grau de exigência), P5(apoio financeiro do Instituto por meio de programas de bolsas e financiamentos) e P24(encontrar uma comunicação precisa sobre os cursos, procedimentos de avaliação e processo de reclamações) - Tabela 8. Comparando as regressões dos alunos com a dos servidores percebe-se que há diferenças entre o número de variáveis significativas, e diferenças de variáveis significativas. Para os alunos houve oito variáveis estatisticamente significativas - P1, P25, P2, P23, P24, P9, P11, P4; para os servidores quatro - P9, P1, P5, P24. Em comum, os dois grupos têm somente P1 e P9, o que permite admitir um Gap de percepções entre as duas amostras analisadas. 
TABELA 7 - PERCENTUAL dE EXPLICAÇÃO DO MOdELO PELAS VARIÁVEIS EXPLICATIVAS (Servidores)

\begin{tabular}{|c|c|c|c|c|c|c|c|c|c|c|}
\hline & \multirow[b]{2}{*}{$\mathrm{R}$} & \multirow[b]{2}{*}{$\begin{array}{c}\mathrm{R} \\
\text { quadrado }\end{array}$} & \multirow[b]{2}{*}{$\begin{array}{c}\mathrm{R} \\
\text { quadrado } \\
\text { ajustado }\end{array}$} & \multicolumn{7}{|c|}{ Estatísticas de mudança } \\
\hline & & & & $\begin{array}{c}\text { Erro } \\
\text { padrão da } \\
\text { estimativa }\end{array}$ & $\begin{array}{l}\text { Alteração } \\
\text { de } \mathrm{R} \\
\text { quadrado }\end{array}$ & $\begin{array}{c}\text { Alteração } \\
\text { F }\end{array}$ & df1 & df2 & $\begin{array}{c}\text { Sig. } \\
\text { Alteração } \\
\text { F }\end{array}$ & $\begin{array}{l}\text { Durbin- } \\
\text { Watson }\end{array}$ \\
\hline 4 &, $391^{d}$ & 153 & 144 & 70527 & 011 & 5,106 & 1 & 381 &, 024 & 2,057 \\
\hline
\end{tabular}

. a. Preditores: (Constante), E9 - conseguir crescimento e desenvolvimento pessoal e profissional com esse curso; E1- o curso possuirá um alto grau de exigência; E5 - apoio financeiro do Instituto por meio de programas de bolsas e financiamentos; E24 - encontrar uma comunicação precisa sobre os cursos, procedimentos de avaliação e processo de reclamações;

b. Variável Dependente: Expectativa geral em relação ao CURSO

Método de estimação: Stepwise

Testes de validez:

- ANOVA: significativo

- Teste de Aleatoriedade: Aceita a hipótese de aleatoriedade

- Teste de Aderência Kolmogorov-Smirnov: Aceita hipótese de aderência à distribuição normal

- Teste de Homocedasticidade: Aceita a hipótese de homocedasticidade

Fonte: Dados da pesquisa. Elaborado pelo autor.

TABELA 8 - EXPECTATIVAS DOS SERVIDORES: variáveis explicativas estatisticamente significantes

\section{COEFICIENTES}

\begin{tabular}{|c|c|c|c|c|c|c|c|c|c|c|c|c|}
\hline Modelo & \multicolumn{2}{|c|}{$\begin{array}{l}\text { Coeficientes } \\
\text { não } \\
\text { padronizados }\end{array}$} & $\begin{array}{c}\text { Coefi } \\
\text { Cien } \\
\text { tes } \\
\text { padroni } \\
\text { zados }\end{array}$ & $\dashv$ & $\frac{\omega}{Q}$ & \multicolumn{2}{|c|}{$\begin{array}{c}95,0 \% \\
\text { Intervalo de } \\
\text { Confiança } \\
\text { para B }\end{array}$} & \multicolumn{3}{|c|}{ Correlações } & \multicolumn{2}{|c|}{$\begin{array}{l}\text { Estatísticas de } \\
\text { colinearidade }\end{array}$} \\
\hline 4 (Constante) & 2,259 & ב,301 & & 7,496 &, 000 & 1,666 & 2,851 & & & & & \\
\hline P9 & 259 & ,058 & 223 & 4,486 & 000 &, 145 & 372 & $\begin{array}{l}, 278 \\
\end{array}$ & 224 & 212 & 902 & 1,108 \\
\hline $\mathrm{P} 1$ & 179 & ,039 & ,221 & 4,554 & ,000 & ,102 & ,257 & 269 & ,227 & ,215 & ,947 & 1,056 \\
\hline P5 &,- 112 & ,035 &,- 157 & $-3,258$ & ,001 &,- 180 &,- 045 &,- 093 &,- 165 &,- 154 & ,955 & 1,047 \\
\hline P24 & ,083 & ,037 & 111 & 2,260 & ,024 &, 011 & 155 &, 150 & ,115 & ,107 & ,921 & 1,086 \\
\hline
\end{tabular}

Variável Dependente: Expectativa geral em relação ao CURSO

Fonte: Dados da pesquisa

Legenda:

P9 - conseguir crescimento e desenvolvimento pessoal e profissional com esse curso;

P1- o curso possuirá um alto grau de exigência;

P5 - apoio financeiro do Instituto por meio de programas de bolsas e financiamentos;

P24 - encontrar uma comunicação precisa sobre os cursos, procedimentos de avaliação e processo de reclamações. 
O infográfico abaixo sintetiza os principais resultados deste estudo:

Imagem 1 - Expectativas: Alunos versus servidores/educadores

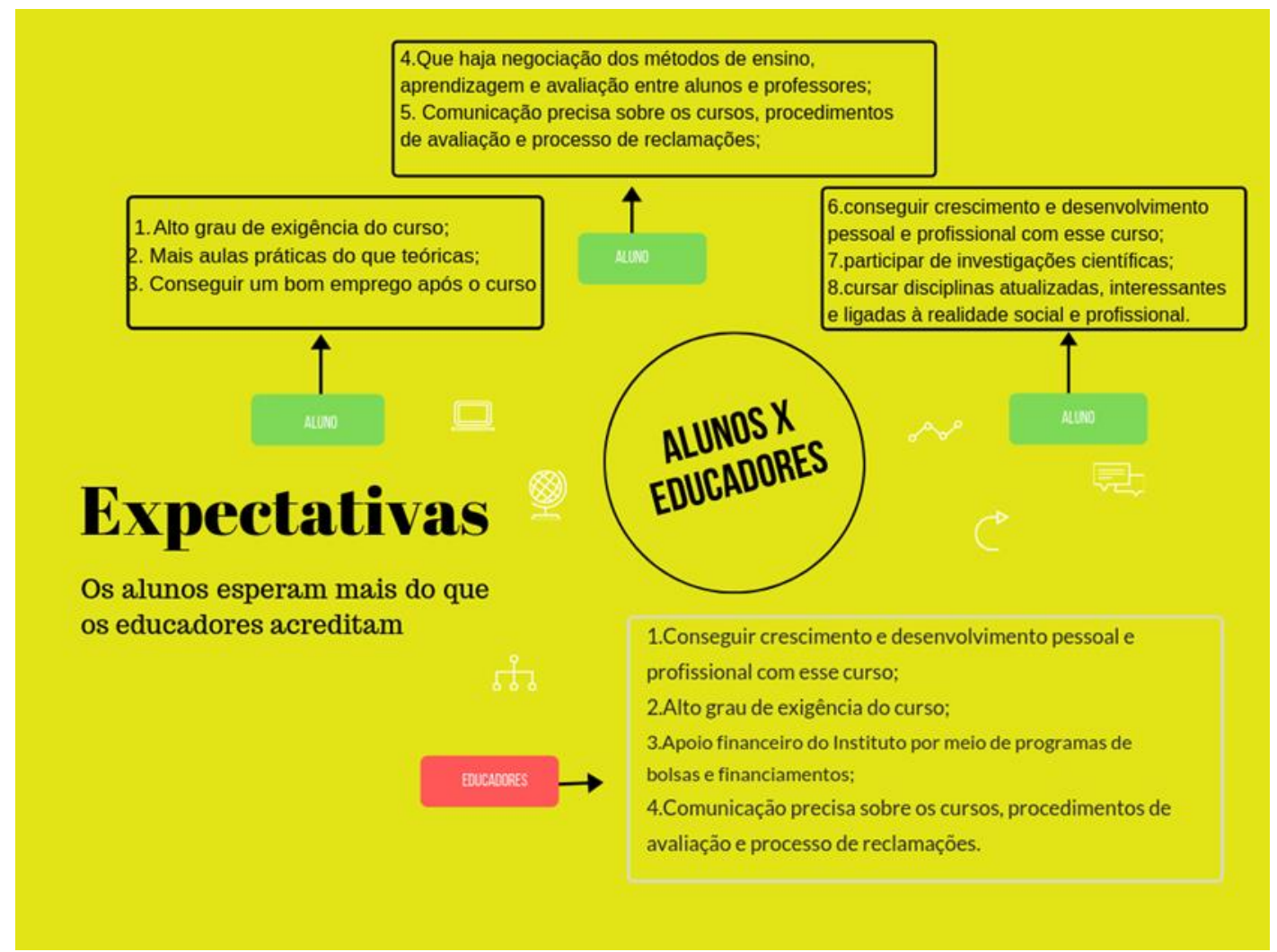

Fonte: Elaborado pelas autoras

Analisando estes resultados, cabe inferir que a IE precisa ampliar seu conhecimento sobre as expectativas dos alunos para que possa construir condições para atende-las. Isso pode tornar a gestão mais eficiente na medida em que as decisões serão tomadas baseando-se em informações mais precisas, como por exemplo, o que os alunos querem além de aula, ou em qual deve ser a prioridade do planejamento orçamentário.

\section{CONSIDERAÇÕES FINAIS}

O objetivo desta pesquisa foi o de identificar o Gap de conhecimento entre o que os alunos esperam de uma Instituição de Ensino (IE) e a percepção que os provedores desse serviço têm sobre o que os alunos esperam quanto às expectativas dos estudantes sobre o curso e a instituição. O gap seria a diferença entre as expectativas que os alunos têm sobre a IE e o curso, e o que os provedores dos serviços dessa IE consideram que sejam as expectativas dos alunos. Os resultados sugeriram este gap, ao apontarem 
que os alunos esperam mais do que os servidores acham que eles esperam. Esses resultados suscitam algumas reflexões.

Primeiro, para que a IE seja capaz de atrair e reter alunos precisa direcionar suas ações para uma formação cidadã que contribua com o desenvolvimento pessoal e profissional, oferecer mais aulas práticas do que teóricas; disponibilizar recursos estruturais e de atendimento.

Segundo, a maior parte das expectativas em relação ao curso apontadas pelos inscritos não foram apontadas pelos servidores, tais como: metodologia; professores exigentes; mais aulas práticas do que teóricas e disciplinas atualizadas e ligadas à realidade social. Tais expectativas, se atendidas, podem aumentar a lealdade dos alunos. Ou seja, a IE precisa alinhar-se ao que espera o seu futuro aluno.

Terceiro, quanto a expectativa geral em relação à instituição, os resultados sinalizaram que os alunos esperam mais aulas práticas do que teóricas; uma boa estrutura física; que a IE tenha fortes ligações com o mercado de trabalho; que também tenha uma comunicação precisa com os alunos; e que os professores utilizem todos os recursos disponíveis para o planejamento do curso e execução das aulas, esperam ainda receber apoio financeiro por meio de bolsas e financiamentos.

Estes resultados contribuem com a literatura no sentido de indicar as expectativas mais almejadas pelos alunos ingressantes no ensino técnico, tanto em relação ao Curso, quanto em relação à IE; e ao evidenciar o gap de percepção no que concerne a todos os servidores da IE que direta ou indiretamente tomam decisões que afetam essas expectativas. Assim, os resultados indicam uma necessidade de a IE conhecer e alinhar-se às reais expectativas dos alunos, com o foco na satisfação e lealdade destes.

Também contribuem no sentido de direcionar os focos de atenção da prestação de serviços educacionais. Assim, pode servir como balizador para a tomada de decisão sobre quais prioridades a gestão educacional pode estabelecer na hora de investir esforços para a satisfação e lealdade de seus principais clientes.

No que se refere às limitações da pesquisa, há alguns aspectos deste estudo que limitam o alcance dos resultados. Um deles é o da generalização. Por se tratar de um estudo feito em apenas uma IE de uma região do país, os resultados não podem ser generalizados para todos os estudantes que pretendem ingressar no ensino público técnico. Nesse sentindo, recomendase a reaplicação desta pesquisa em outras regiões, bem como em outras IE, inclusive em particulares. Ademais, podem existir expectativas de alunos que não foram investigadas por este estudo.

Portanto, sugere-se que sejam feitas novas pesquisas que busquem identificar novas expectativas de alunos ingressantes, bem como o estudo do gap 5, do Modelo dos 5 Gaps, que é aquele que evidencia a percepção dos 
alunos antes e depois do recebimento dos serviços, pois o presente estudo, apresentou as expectativas dos alunos antes de receberem os serviços educacionais. Cabe, portanto, investigar se tais expectativas foram atendidas no final do curso, aplicando-lhes novo questionário para apurar. Seria importante para a validação de expectativas já testadas e para indicar quais ações a IE pode implementar para melhorar seus resultados.

\section{REFERÊNCIAS}

BRASIL. Lei n. 9.394, de 20 de dezembro de 1996. Estabelece as diretrizes e bases da educação nacional. Diário Oficial da República Federativa do Brasil, Brasília, DF, ano 134, n. 248, p. 27.833-27.841, 1996.

CASTRO, Luiz Alberto Marcondes Homen de Mello e. de; NISHIMURA, Augusto Takerissa; SILVA, Clarisse Monteiro; MADUREIRA, Bruno Maciel;

CASADO, Tania. Expectativas e Satisfação dos alunos de graduação em administração da FEA-USP/SP em relação aos estágios. REGE Revista de Gestão, v. 14, n. especial, p. 61-76, 2007.

DAVIES, Sarah. Marketing in higher education: matching promises and reality to expectations. Responding to Student Expectations, p. 103-114, 2002.

IFMA. Instituto Federal do Maranhão. Notícias. Disponível em: <http://portal.ifma. edu.br/2015/10/08/ ifma-tem-29-932-inscritos-no-processoseletivo-2016/>. Acesso em: 13 out. 2015.

LIMA, Licínio. C. A avaliação institucional como instrumento de racionalização e o retorno à escola como organização formal. Educação e Pesquisa, São Paulo, v. 41, n. especial, p. 1339-1352, 2015.

MAINARDES, Emerson Wagner; ALVES, Helena Maria Batista.; RAPOSO, Mário. Identifying stakeholders in a Portuguese university: a case study. Revista de Educación, v. 362, p. 429-457, 2013.

; DOMINGUES, Maria José Cardoso de Souza. Satisfação de estudantes em administração de Joinville/SC. Revista Pensamento Contemporâneo em Administração, v. 4, n. 2, p. 76-94, 2010.

MALHOTRA, Naresh. Pesquisa de marketing: uma orientação aplicada. 4. ed. Porto Alegre: Bookman, 2006.

MARGOTTO, Sulyana Comério. Expectativas dos alunos no ensino superior: uma análise do gap entre a percepção de alunos e professores. Dissertação (Mestrado em de Ciências Contábeis). Fundação Instituto Capixaba de Pesquisa em Contabilidade, Economia e Finanças (FUCAPE), Brasil, 2014. 
MARIMUTHU, Malliga; ISMAIL, Ishak. Service Quality in Higher Education:Comparing the perceptions of stakeholders. Nith AIMS International Conference on Management, p. 1-4, 2012.

MARINHO-ARAUJO, Caisy. Maria; FLEITH, Denise de Souza; ALMEIDA, Leandro Silva; BISNOTO, Cynthia; RABELO, Mauro Luiz. Adaptação da escala expectativas acadêmicas de estudantes ingressantes na educação superior. Avaliação Psicológica, v. 14, n. 1, p. 133-141, 2015.

MICHAEL, Steve O. American higher education system: consumerism versus profissorialism. The International Journal of educations management, v. 11, n. 3, p. 117-130, 1997.

MIGUEL, Paulo Augusto Cauchick; SALOMI, Gilberto Eid. Uma revisão dos modelos para medição da qualidade em serviços. Revista Produção, v. 14, n. 1, 2004.

PARASURAMAN, Arun; ZEITHAML, Valarie A; BERRY, Leonard L. A conceptual model of service quality and its implicafions for future research. The Journal of Marketing, v. 49, p. 41-50, 1985.

Scale. Journal of Retailing, v. 67, p. 420-50, 1991.

TEEROOVENGADUM, Viraiyan; KAMALANABHAN, T. J.; SEEBALUCK, Ashley Keshwar. Measuring service quality in higher education Development of a hierarchical model (HESQUAL). Quality Assurance in Education, v. 24, n. 2, p. 244-258, 2016.

XAVIER, Rodrigo Navarro. Avaliação da qualidade dos serviços de uma instituição de ensino superior utilizando a aplicação do modelo adaptado de mensuração dos 5 Gap's. Revista Capital Científico, v. 7, n. 1, 2010.

ZEITHAML, Valaire A.; PARASURAMAN, A.; BERRY, Leobard L. Delivering Quality Service-Balancing Customer Perceptions and Expectations, $p$. 226, 1990. 